\title{
Digital challenges for creative industries: case of opera
}

\author{
Nina Trubnikova*, and Severyan Tsagareyshvili \\ RUDN University, 117198, Miklukho-Maklaya str.6, Moscow, Russia
}

\begin{abstract}
Digital technologies today are seen as a powerful driving force of creative industry growth. The authors reveal the development of operatic theatre as a significant entity of a new market reality - the economy of impressions. Notwithstanding the fact that the majority of opera houses are state funded, the issue of economic efficacy is gaining relevance for theaters; increasingly more attention is paid to promoting theatrical product. Despite the fact that the eliteness of operatic art and loyalty to tradition poses restrictions on implanting new instruments of theater branding. active digitization of the opera product is the only plausible means of attracting the attention of the new generations who are used to this format of representing cultural content. This dilemma is analyzed in the article on the basis of the data yielded by a field study in the form of a survey involving Russian and Italian opera lovers.
\end{abstract}

\section{Introduction}

The processes of digitization today have concerned creative structures and industries which in the past remained practically unaffected by new technological shifts and, for quite a while, underwent zero digital development. This brings to the fore the problems of introducing digital technologies in the products of classical theater, including musical theater with its synthetic nature. Operatic art, among the others, has to face the challenge. The genre that for centuries remained a highly conservative one is now confronted with the vital necessity of looking more attractive for the new generation of listeners. The intense competition with the colorful multimedia content of the mainstream culture along with the massively emerging alternative kinds of entertainment make the issue of financial health especially relevant for opera houses [1, p. 1].

The key driver of technology-related growth for the industry of performing arts can be regarded as their ever-growing need to employ informational/communicational technologies for increasing the spectacularity and uniqueness of their content [2, p. 413]. The potential level of monetization of their product (ticket price, overall revenue of the theater etc.) directly depends on the extent to which the product meets the expectations of the audience.

The restricted offline communication brought about by the COVID-19 pandemic urged the opera to set out on a qualitative digital reform [3, p. 45]. The reorganization, in fact, had begun long before the said events, but for a while it did not receive a wide spreading, nor, more importantly, support of the loyal operatic art consumers. Due to the recent

${ }^{*}$ Corresponding author: trubnikova_nv@rudn.ru 
communicational lockdown the theaters that used to regard direct live interaction with the spectator as their main channel, now have found themselves under the threat of a financial and HR collapse. In consequence, they have been forced to urgently adapt opera products to digital placement. Online resources, which were normally just a complementary means, have suddenly become the only channel of communication with the consumers.

Overall online sales of cultural products across the industry doubled in 2020, reaching the record $\$ 12.4$ bn, while the market share of the sector increased to $25 \%$ compared to $9 \%$ the year before [4]. The merging of the technological and creative spheres is only expected to intensify in the nearest future [5, p. 2].

The problem of the research is rooted in the fact that, in the digital era, the traditional marketing paradigm which extended onto opera as an art and an elite show business, undergoes an inevitable transformation.

Marketing, which in the pre-digital economic system existed as an outer auxiliary function in the sphere of operatic art, never used to affect the creative core. Now, however, it is expanding its frontiers. Marketing today is integrating with theater, while beginning to actively form a new opera product, seeking new points of contact with the consumers of different ages, including the younger generation. Formation and transformation of the operatic product by use of digital instruments is not always unilaterally understood and unanimously accepted by the audience. This is why researching the audience's attitude towards the potentials and limitations of introducing such instruments in the process of creating and promoting opera is an important academic and practical task for effective management of the modern opera theater and for shaping its communication strategy. Digital technologies have provided the industry of PR and marketing with new complex methods for evaluating demographic and behavioral characteristics of the consumers who leave informational traces of their presence [6, p. 25], as well as for using this information to form marketing strategies [7, p. 172].

Today, one of the main drivers of transformational processes in cultural economy in the conditions of digitization is the steady growth of "culture of participation" [8, p. 86] presupposing interaction of the "networking public" with the media space [9] which optimizes dialogue between the audience and a cultural organization. Kaiser defines the use of digital technologies by cultural organizations as a special strategy able to fundamentally change the consumers' perception of a given cultural entity [10, p. 132]. It completely reorganizes the traditional creative industries of design, production, consumption, service and plays an important innovational role for their development. On the one hand, creative entities can receive inspiration, financial backing and talent support through of audience analysis, crowdfunding and crowdsourcing with the help of the Internet. [11]. On the other hand, creative institutions can keep in touch with their consumers at a distance on the basis of online platforms. They can quickly register the dynamics of creative demand and select creative products for the consumers with precision and accurate timing.

The so-called virtual agglomeration of creative industries is quickly expanding as it positively influences the life of creative industries, including the development of opera.

The existence of digital technologies generate new commercial opportunities for operatic institutions - such that extend beyond the boundaries of traditional merchandising and published products (programs, billboards etc.) [12]

The authors of this research single out three types of digital impact as applied to operatic art:

- Acting on the operatic product per se - introducing technologies in the show itself (digital lighting, sound, effects, props)

- Optimizing distance demonstration of the operatic content through airing and online streaming, as a compensation for the absent live sound. This same purpose is also served by digital libraries of opera houses and halls as well as by professional recordings and 
demonstrations involving technologies of virtual and augmented reality; by digitizing and archiving best performances and concerts.

- Engaging new technologies as means of promotion for operatic art and for drawing a wider audience. This concerns such formats as advertising in social networks, digital PR communications, and some non-standard instruments (advergaming, virtual excursions to opera halls etc).

A special place in this regard is occupied by representing opera organizations in social media through application of SMM (social media marketing) instruments. Operatic institutions use social networks for spreading information about their activities and shows given for real and potential audiences [13]. Filling social media with relevant content has a whole range of functions, like informing the audience about forthcoming events, building up loyalty via effective direct marketing (communicating with the audience in comments and direct messages), targeted advertising, drawing new consumers by means of influencer marketing (live streamings and online interviews with famous singers, producers, conductors).

\section{Materials and methods}

The aim of the research is to reveal the attitude of the consumers (opera lovers) in Russia and abroad towards engaging digital technologies in operatic art and towards digitized promotion of opera products in and outside Russia. The authors also aim to evaluate the effectiveness of such tools in terms of monetizing and optimizing the activity of opera halls in the "Covid19"- and "post-Covid-19" periods.

In connection with the overall digitization tendency of cultural industries and the necessity of revealing its specifics in regard to opera theaters, the authors have formulated several key questions of the research:

How do operatic product consumers in Russia and abroad feel about involvement of digital instruments in opera?

To what degree are the consumers aware of the directions and technologies of digital transformations in operatic industry; do they use digital resources of musical organizations?

Can digital analogues of opera products eventually replace the traditional formats?

The hypothesis of the research is that the audience regards digital technologies as an effective instrument of popularizing opera, a mark of its adaptability to the realities of the digital society, and, consequently, a token of opera theaters' economic thriving.

For conducting the research the authors have chosen the empirical method of surveying on Google Forms, which is one of the most optimized platforms for this type of study. The research engaged a standardized questionnaire and was done exclusively in the online medium, as this was in complete conformity with the topic of the survey. In the course of the work the authors applied such research methods as comparing and generalizing. The research mainly focused on respondents from two countries - Russia and Italy, as one of the world opera centers. The motivation to take the survey was modeled by the corresponding motivational post Surveys in the Russian and Italian languages which were circulated from 17 December 2020 to 10 January 2021 via two large opera-dedicated groups in social networks. Representativity of the respondents selection is ensured by the narrow thematic character of the groups, all the members of which are opera lovers, i.e. the target audience of the research.

As the platform for the Russian survey the researchers have chosen the group "Voci dell'Opera" [14] based in the most popular Russian social network VKontakte. The group is of an open character; the number of subscribers as of 13 January 2021 amounted to 55606 persons, making Voci dell'Opera one of the widest spread Russian thematic opera-oriented communities. The group is described as a sort of art-featuring magazine whose aim is to 
reveal the opera world to a wide circle of followers, as well as acquaint the public with ballet, academic vocal and classical music in general. The community covers opera music and theatre, old-time and today's singers, musical shows and related events; makes and publishes musical compilations along with advertising music festivals, opera schools and academies, airings, books featuring and covering opera etc. The group's Instagram account and Internet site - http://www.vocidellopera.com - republish most of the information posted by the community.

The survey in Italian was conducted in Facebook, the reference group being called L'Opera lirica dal Loggione \& Musica in Opera [15]. This community has fewer subscribers than Voci dell'Opera (13330 persons as of 13 January 2021, over 9000 of this amount being native Italians). Just like the Russian group, this one, too, publishes information concerning operatic shows and airings. The subscribers have a tradition of exchanging observations and views. The comments feature active discussions and parallels drawn between the modern and retro worlds of opera.

The questions of the survey are based on the following:

- Social and demographic data of the participants (gender, age, place of residence);

- The participants' overall regard of digital technologies as applied to operatic art and the process of advertising opera;

- The participants' level of awareness of the fact that digital technologies are used in the world of opera (if they themselves have often encountered examples of this);

- The participants' involvement in digital platforms of musical organizations as well as social networks; if the content of those is useful to them;

- The potentiality of a live show being substituted for by a digital equivalent online.

The overall amount of respondents in the survey is 325 people (210 Russians and 115 Italians).

The Russian survey comprised $57,7 \%$ female and $42,3 \%$ male participants; the Italian one - 50,4\% female and 49,6\% male respectively. The participants were divided into groups according to age - a traditional grouping for this kind of sociological study: 15-24, 25-44, 45 64 и $65+$.

Most Russian participants (57,7\%) fall in the 45-64 age group; next come 23,7\% of those aged 25-44. Those are followed by $11,3 \%$ aged $15-25$, and $7,3 \%-65+$. The majority of the Italians occur in the 45-64 age group (49,5\%), followed by the $25-44(27,3 \%)$. The respondents $60+$ amount to $17,2 \%$, those under 20 - to $6 \%$.

It can be thus inferred that both in Russia and Italy the most opera lovers are 45-64 years old, while respondents under 20 are almost not featured at all in this survey. Meanwhile, Italy yields notably more $65+$ participants, whereas in Russia they amount to under $10 \%$.

The age grouping of the participants is representative and largely corresponding to other studies of target audiences in the realm of classical music. The Statista study [16] showed the majority of classical music listeners to be $55+$, whereas $35 \%$ of the classics' followers are under 35.

The choice of an online platform and the thematic particularity of the study account for the low amount of senior participants $(65+)$, while the age of many respondents occurs just in the "representative" slot between 55 and 64 .

The Russian participants were represented by residents of many different regions: the majors like Moscow, Saint-Petersburg, Novosibirsk, Voronezh, Omsk, Samara, Perm and Volgograd; and medium-sized towns like Vladimir, Kursk, Krasnodar, Habarovsk, Ryazan and others. The featured overseas territories are Ukraine (Odessa, Lugansk, Novorossiisk), Belarus (Minsk), Israel (Holon, Modiin), Germany (no city/town specification), Austria (Graz).

All the participants of the Italian survey, too, hail from different towns and provinces of Italy: the major centers like Milan, Rome, Naples, Turin, Venice, Genoa, Palermo, Florence, 
Verona, as well as the medium-sized ones - Ferrara, Padua, Modena, Brescia, Rimini, Bergamo, Taranto, Livorno, Lecce, Salerno. The Italian survey also featured residents of small towns like Sant'Agata di Militello.

\section{Results and discussion}

The respondents' evaluation of the new stage of operatic art development with application of digital formats has confirmed the idea that, far from being in decline, the industry of performing arts in the segment of opera is gradually developing in spite of the financing problems. This idea has also been corroborated in the course of the expert interviews with participants of the industry, who state that, although traditionally the sphere of performing arts is one of the most difficult objects for result-oriented management, digital technologies facilitate the task.

The hypothesis that introducing digital technologies (in the show itself as well as in promotional instruments) on the whole improves the perception of this art has been supported by the respondents. Almost half of the participants in the Russian group (44,9\%) gave the response "rather yes than no" to the question about approving the use of digital instruments.

$20,4 \%$ gave a unilaterally positive answer (“definitely yes"). The Italian opera lovers appeared a bit less enthusiastic: $40,8 \%$ more or less positively evaluate the change in question, and $17,1 \%$ give a unilaterally positive reply. Notwithstanding the fact that the development of Italy in the main digitization spheres is highly active, such a rather chilly attitude towards digital instruments in opera is accounted by the fact that opera is a cult in the country, and the classical boundaries of this art are carefully preserved.

The survey has also measured the level of the respondents' awareness of concrete digital instruments that are being integrated in opera today.

Next question is connected with particular innovational technologies in the fields of opera which the participants have observed in real life. The frequency of encounter with certain innovational formats reflects the degree of integration of these technologies in the modern opera, as well as how noticeable they are for the consumers, and if they have become part of the modern opera world, an effective means of its promotion and popularizing.

The respondents were asked to chose between several options: mobile applications of theaters and opera houses, viewing a show in 3D glasses, video games with opera-based plots, digital billboards in town.

The results (figure 1) showed that, on the whole, the Italian audience is much better informed about different opera digitization formats than the Russian counterparts. The Russian respondents who have never encountered digital technologies in the opera are twice more numerous than the Italian ones.

It is also worth noting that such an instrument as AR- and VR-technologies which is receiving an increasingly wider spreading in western theaters is hardly familiar to the Russian audience and barely in demand of opera producers and decorators in Russia (only 12,2\% of the Russian respondents happened to be aware of it).

Table 1. The awareness of digital instruments in opera as demonstrated by the Russian and Italian audiences.

\begin{tabular}{|l|c|c|}
\hline \multicolumn{1}{|c|}{ Innovational technologies in opera } & $\begin{array}{c}\text { Russian } \\
\text { respondents }\end{array}$ & $\begin{array}{c}\text { Italian } \\
\text { respondents }\end{array}$ \\
\hline Mobile apps of theaters and halls & $52,3 \%$ & $61,5 \%$ \\
\hline Viewing performances in 3D glasses, AR- u VR-technologies & $12,2 \%$ & $56,6 \%$ \\
\hline Video games with operatic plots & $12,2 \%$ & $13,8 \%$ \\
\hline Digital billboards & $36,6 \%$ & $44,4 \%$ \\
\hline Never observed & $16,2 \%$ & $7,7 \%$ \\
\hline
\end{tabular}


This question presupposed adding individual answers. Among the variants of digital technologies listed by the Russian respondents were:

- online airings, online concerts and streams;

- $\quad$ interviews and coaching online;

- $\quad$ introducing video clips in the show;

The Italians listed the following digital-instruments:

- online broadcasting and streaming;

- online concerts featuring animation films.

It also appeared relevant to obtain information whether the respondents used social networks of theaters and philharmonics, for, as was noted above,

SMM today is one of the most important digital instruments for opera organizations. More than

$40 \%$ of the respondents in both cases $(42 \%$ и $44,9 \%$ in the Russian and Italian groups respectively) are subscribed operatic social media and regularly follow their contents. Meanwhile there are also respondents who do not use social networks (33\% in the Russian group and $25,5 \%$ - in the Italian). $25 \%$ и $29,6 \%$ Russian and Italian opera goers respectively are subscribed to opera theaters' accounts but do not follow the content.

Among the social networks used by respondents, the most popular are:

Vkontakte $(46,9 \%)$ in the Russian group and Facebook (50\%) in the Italian. Instagram, YouTube и Twitter are more popular among the Italian respondents, although they are also actively used by the Russians.

Apart from other aspects, the research analyzed the participants' opinion whether live operatic sound could be replaced by online streamings.

More than a half of the surveyed (54,5\% Russians and 56,5\% Italians) believe that online broadcastings are in no way able to compete with a real performance. $39,4 \%$ of Russian- and $36,5 \%$ Italian respondents accept the possibility of replacement as a partial thing. Less than $10 \%$ in both cases are willing to replace a live performance with its online version.

Situational marketing changes the communicational picture of the world according to the concrete informational call. Such a call has recently become the COVID-19 pandemic which has proved the toughest check for the opera industry. The life of the theater was completely stopped, and the only thing left to do for opera houses around the globe was show online broadcastings of their best recent years performances.

According to the data on frequency of viewing online broadcastings during the pandemic, this form of representing operatic art in the digital medium was not in high demand even in the time of the pandemic. $41,8 \%$ of the Russian- and $42,9 \%$ Italian respondents watched the online shows "several times". $37,8 \%$ and $29,6 \%$ participants respectively did not watch them at all, while only $20,4 \%$ and $27,5 \%$ watched them regularly.

The final stage in the survey was the question what the respondents would choose in case of not being able to go to the opera house: watch broadcastings, listen to old recordings, or complete abstain from listening to opera music. Most respondents in both cases chose to refuse the digital equivalent of a live performance, and preferred classical recordings to modern broadcasts. $32,3 \%$ of Russian respondents are willing to watch online streams, against only $39 \%$ of Italian counterparts. $16,2 \%$ and $16,5 \%$ Russian and Italian participants respectively choose to live without listening to opera at all if real theater is inaccessible. Having analyzed the results of the online survey, we have come to the following conclusions:

- Most participants from both Russia and Italy feel that introducing digital technologies in operatic art is a positive factor, and believe that these technologies can improve the perception of opera today.

- A wide circle of the respondents have encountered digital technologies in opera and in its promotion, which reflects active presence of this technologies in the communicational 
field and proves that they are visible to the consumers, while the Italian audience is a lot more aware them than the Russian

- Most respondents are subscribers and regular followers of operatic social media

- Meanwhile, a significant amount of the participants refuse to accept replacement of live theater with its online version regarding such a change as impossible

- Online broadcastings which replaced real theatrical live in the time of the pandemic were only viewed by a limited number of the consumers: most of them would choose to listen to old classical recordings.

\section{Conclusions}

The process of digitization of opera is not only a musical and cultural, but also a marketing and economic issue, for it directly affects stability of the theater, the size of investment in it, its creative projects. From the point of view of integrating new instruments in the operatic show and using them for promoting the cultural product, the respondents see these instruments as a positive influence on modern perception of opera. This concerns innovations in the opera content itself (unusual, spectacular technologies attracting the audiences' attention) as well as interactive channels of informing the consumers, such as social networks. The practice of online streamings as an additional activity of operatic institutions successfully services their brand, expands their geography, intensifies the interest of potential viewers. With such an approach, digital formats and platforms do not lead to the crisis of live performing, denaturation of the art and loss of its meaning [17, p. 4].

The moot point, however, remains the possibility of opera "going online" as a new phenomenon which is equalized to traditional theater, and where live sound is replaced with digital "formula". On the one hand, a number of respondents view this a chance to see events that would be inaccessible offline, on the other - the majority feel that it is important that the theater should remain authentic and that its real acoustic core should remain intact.

The research had shown that the opera theater tradition remains firm and, even in the conditions of a pandemic, "switching online" is not always received with a welcome, or proves a successful promotional move.

Thus, it can be concluded that, in today's reality, digital technologies are important, but only additional tools for promoting live opera. They must not change the traditional artistic essence of opera, but harmoniously augment it, while also meeting the requirements of modernity. This is the main difficulty of adapting a conservative genre like opera to the digital reality of today. Time alone will show if, while preserving the integrity and traditions of the operatic theater, digital technologies will be able to attract new audiences as well as increase the loyalty of the existing ones.

\section{References}

1. A. Modlinski, L. M. Pinto, Management-journal of Contemporary Management Issues, 25, 1 (2020)

2. I. Lacasa-Mas, I. Villanueva-Benito, Profesional de la Informacion, 5(4), 413 (2012)

3. O. Obradovic, M. Senicic, IPSI BGD Transactions on Internet Research, 17(2), 45 (2021)

4. Worldwide art sales fall by $22 \%$ in 2020 , Interfax, https://www.interfax.ru

5. I. Sedykh, Industry Performing Arts, National Research University Higher School of Economics (2018) https://dcenter.hse.ru 
6. I. Dickey, W. Lewis, Handbook of research on digital media and advertising: User generated content consumption, 1 (2011)

7. Sh. Rodgers, E. Thorson, Routledge, Digital advertising: theory and research (3rd edition) (2017)

8. G. Crawford, V. Gosling, G. Bagnall, B. Light, Information Communication Society, 17(9), 1072 (2014)

9. M. Ito, Introduction (Networked publics London: MIT Press, 2007)

10. M. Kaiser, The Cycle: A Practical Approach to Managing Arts Organizations (Brandeis University Press, 2013)

11. X. Chen, C. H. Liu, C. C. Gao, Y. Jiang, Sustainability, 13(14) (2021)

12. F. Avanzini, A. Baratè, G. Haus, L. A. Ludovico, S. Ntalampiras, HCI, 12515, 325 (2020).

13. L. Wroblewski, Culture Management: Strategy and Marketing Aspects (Berlin: Logos Verlag Berlin GmbH, 2017)

14. Voci dell'Opera' VKontakte, https://vk.com/operavoci

15. L'Opera Lirica dal Loggione \& Musica in Opera', Facebook, https://www.facebook.com/groups/musicainopera

16. Distribution of classical music listeners worldwide as of the 4th quarter of 2018 , by age group, https://www.statista.com

17. C. Pernelet, European overview of the use of digital media for opera, music and dance education, European Network for Opera and Dance Education (2015) https://www.reseo.org 